\section{Medical Principles} and Practice

\author{
Vinod K. Grover ${ }^{\mathrm{a}}$ \\ Salim M. Adib b \\ Leons Joseph ${ }^{\mathrm{a}}$ \\ Ali M. Ali Nur a \\ a Department of Surgery, \\ Al-Jahra Hospital, and \\ b Department of Community \\ Medicine, Faculty of Medicine, \\ Kuwait University, Kuwait
}

\section{Key Words}

Scrotum

Swelling

Torsion

Appendages

Children

Adolescents

\title{
The Etiology of Acute Scrotal Swelling on Surgical Exploration among Children and Adolescents in Jahra
}

\begin{abstract}
Objective: To describe the clinical presentation as well as the outcome of surgically explored acute scrotal swellings among children and adolescents recorded at the Al-Jahra Hospital, Kuwait during the period 1985-1995. Methods: Hospital records of 120 cases were reviewed. Results: Seventeen percent of the cases were found to be testicular torsions (TT) and 40\% torsions of testicular appendages (TAT). Other etiologies included traumatic swelling (15\%), idiopathic edema (13\%), epididymo-orchitis (10\%), hydroele (4\%) and others (2\%). Ages of patients ranged from 6 months to 18 years, averaging 9.3 years $(\mathrm{SD}=2.9)$ for TAT cases and 10.1 years $(\mathrm{SD}=6.4)$ for TT cases. Swelling and pain were located on the left side for $65 \%$ of the torsion cases. Direct trauma was reported in $22 \%$ of the torsion cases. In $90 \%$ of TT cases, orchidopexy was performed with success. Subsequent testicular atrophy occurred in only 1 patient who had symptoms for more than $48 \mathrm{~h}$ prior to surgery. Orchidectomy was directly performed on necrosed testes in a patient with signs lasting more than $48 \mathrm{~h}$, and another patient with signs lasting 4 days. Conclusions: Primary health care physicians in Jahra district should continue to educate parents and adolescents to recognize the gravity of scrotal pain, and the importance of early response as a way of avoiding testicular necrosis.
\end{abstract}

\begin{tabular}{ll}
\hline KARGER & ○ 1998 S. Karger AG, Basel \\
Fax +41 61 306 12 34 & 1011-7571/98/0073-0192\$15.00/0 \\
E-Mail karger@karger.ch & Accessible online at: \\
www.karger.com & http://BioMedNet.com/karger
\end{tabular}

Dr. Salim M. Adib, MD, DrPH

Department of Community Medicine

Faculty of Medicine, Kuwait University

PO Box 24923

13110 Safat (Kuwait) 


\section{Indroduction}

Acute scrotal swellings (ASS) are painful conditions found mainly in children and adolescents. Most common causes of ASS are torsions of testes (TT) or of testicular appendages (TAT). A TT that is not corrected will lead to necrosis in a few hours, depending on the severity of the torsion $[1,2]$. Quite often the physical examination and available investigations are not helpful in ruling out the diagnosis of torsion. Since TT is a surgical emergency, surgery is often performed even when other diagnoses cannot be ruled out. This paper reviews surgical explorations of ASS performed at the Al-Jahra Hospital, in the NorthWestern district of the State of Kuwait, between 1985 and 1995. It describes the clinical presentation of ASS cases, and the immediate surgical outcomes of cases diagnosed as torsion.

\section{Methods}

The Al-Jahra Hospital is the only tertiary care center in the Jahra district, an area with an estimated settled and nomad population of up to 250,000 in 1995 [3]. Utilization patterns indicate that, while some patients on the outskirts of the district may choose to seek medical care outside the area, most Jahra residents normally seek care in Al-Jahra Hospital.

Records of all patients aged 18 years and less, operated at the Al-Jahra Hospital for ASS between November 1985 and November 1995, were retrieved. The review was limited to that age-group as TT, the major clinical challenge posed by ASS, is relatively rare in older ages. Cases of abscesses and infected scrotal wounds were excluded as their diagnosis is evident and does not usually require more than local care. Cases of strangulated inguinal hernia were also excluded as these cases belong more properly to abdominal surgery. Cases of TT or TAT were particularly reviewed. For these cases, the following variables were extracted: age of patient, side of swelling, presence of systemic signs and relevant past medical history. Details of the physical examination, routine blood and urine laboratory tests, and Doppler ultrasound test results were also reviewed. It must be noted that, while routine tests are performed for all patients, the Doppler test is not. That technique became available in Jahra only in the last year of this review, and is generally not used for infants and children less than 15 years of age. Also included in the review variables were operative, immediate and short-term follow-up findings.

All variables were presented as frequencies for categorical ones and means with standard deviations (SD) for continuous ones. When means were compared, the Student's t test was used to assess statistical significance, while chi-square test was used when comparing frequencies. Results with a $p$ value $\leq 0.05$ were considered significant. Data entry and analysis were conducted using SPSS/Windows.

\section{Results}

Records of 120 surgical explorations of ASS among patients 18 years and younger were found in the 10-year review period. These explorations involved 119 patients. One child was admitted for TAT on either sides, at two separate times. Of the 120 explorations, 68 cases $(57 \%)$ were diagnosed as TT $(\mathrm{n}=20)$ or TAT $(\mathrm{n}=48)$. In addition, $15 \%$ $(n=18)$ of explored cases had a known direct trauma to the genital area. In these cases emergency surgery was justifiable in order to assess the traumatic damage, evacuate a scrotal hematoma and/or repair a ruptured testis and the surrounding tissue. In 9 such cases, orchidectomy was performed for ruptured testes, blood was evacuated and the tunica albuginea repaired. Fourteen cases (13\%) were found with idiopathic scrotal edema upon exploration. All these cases were children less than 7 years old who had presented with scrotal swelling, redness and tenderness simulating incomplete torsions. Twelve ASS cases $(10 \%)$, all aged $12-18$ years, were found with epididymo-orchitis. Of these 12,9 had leukocytosis and only 3 were febrile. Surgical exploration was conducted nevertheless, as systemic signs may occur with torsions, and 
Table 1. Etiologies of acute scrotal swellings in children and adolescents investigated surgically at Al-Jahra Hospital, Kuwait, 1985-1995 ( $\mathrm{n}=120$ cases)

\begin{tabular}{|c|c|c|c|c|}
\hline & \multicolumn{2}{|c|}{ Cases } & \multicolumn{2}{|c|}{ Age, years } \\
\hline & $\mathrm{n}$ & $\%$ & mean & SD \\
\hline TAT & 48 & 40 & 9.3 & 2.9 \\
\hline TT & 20 & 17 & 10.1 & 6.4 \\
\hline $\begin{array}{l}\text { Traumatic swelling without } \\
\text { torsion }\end{array}$ & 18 & 15 & 9.5 & 3.0 \\
\hline Idiopathic scrotal edema & 14 & 13 & 5.0 & $1.1^{*}$ \\
\hline Epididymo-orchitis & 12 & 10 & 15.7 & $2.6^{*}$ \\
\hline Hydrocele & 6 & 4 & 6.2 & $2.6^{*}$ \\
\hline Henoch-Schönlein vasculitis & 1 & 0.5 & 7.0 & NA \\
\hline Benign intratesticular dermoid cyst & 1 & 0.5 & 1.5 & NA \\
\hline Total & 120 & 100 & 9.4 & 3.2 \\
\hline
\end{tabular}

$* \mathrm{p}$ value $<0.05$ (reference: mean age of TAT cases).

$\mathrm{NA}=$ Not applicable because of small numbers. noninvasive exploration techniques were not available. Six cases $(5 \%)$ were found with hydrocele and no torsion of testicular contents.

One 7-year-old boy was admitted for brutal onset of left scrotal pain and swelling, with a fever at $39^{\circ} \mathrm{C}$. The testis, epididymis and spermatic cord were englarged and tender. Laboratory tests showed leukocytosis and bacteriuria. Despite a clinical presentation suggestive of epididymo-orchitis, and in view of the abrupt onset of the painful swelling, surgical exploration was conducted to avoid missing a TT. The exploration was negative, but a generalized purpura developed the following day, leading to the suspicion that the scrotal swelling may have been a manifestation of Heinoch-Schönlein vasculitis. The diagnosis was later confirmed on blood tests, and the signs of disease disappeared within days under supportive treatment.

One 18-month-old boy was admitted for left scrotal pain and swelling of 7 days' duration. The testis was enlarged, tender, and a juxtatesticular nodule was palpable. A diagno- sis of torsion of a cyst of Morgagni was made. Upon exploration, a benign intratesticular dermoid cyst was found and removed. Orchidectomy was done to avoid any potential malignant transformation in remnants of the cyst.

Ages of patients ranged from 6 months to 18 years, averaging 9.3 years $(\mathrm{SD}=2.9)$ for cases of TAT, 10.1 years $(\mathrm{SD}=6.4)$ for cases of TT and 9.5 $(\mathrm{SD}=3)$ for traumatic ASS. The mean age of TT and traumatic ASS cases did not vary significantly compared to that of TAT cases. Significant differences in mean ages were found, however, for some other ASS etiologies as seen in table 1 . There were no seasonal differences in the incidence of torsions in this series.

The presenting signs and symtoms for torsion cases are shown in table 2 . Two patients had contralateral TAT: one was operated twice at Al-Jahra Hospital, while the other had already been operated upon, on one side elsewhere. Time of onset of pain prior to presentation ranged from few hours to 4 days in TT, and from 1 to 10 days in TAT. Up to $65 \%$ 
Table 2. Presenting symptoms and signs in cases of torsion of scrotal contents, Al-Jahra Hospital, Kuwait, 1985-1995

\begin{tabular}{lcc}
\hline & $\begin{array}{l}\text { TT } \\
(\mathrm{n}=20)\end{array}$ & $\begin{array}{l}\text { TAT } \\
(\mathrm{n}=48)\end{array}$ \\
\hline History of direct trauma, \% & 15 & 25 \\
Onset of pain* & hours-4 days & $1-10$ days \\
$\quad$ Started $<12 \mathrm{~h}$ ago, \% & 50 & 0 \\
$\quad$ Started $<24$ h ago, \% & 15 & 35 \\
$\quad$ Started $<48$ h ago, \% & 20 & 17 \\
$\quad$ Started $>48$ h ago, \% & 15 & 48 \\
Swelling, \% & 100 & 67 \\
Left side affected, \% & 60 & 67 \\
Fever, \% & 10 & 19 \\
Leukocytosis, \% & 36 & 25 \\
Palpation & & \\
$\quad$ Tenderness of testes, \% & 100 & 100 \\
$\quad$ Enlargement of testis and/or & & \\
$\quad$ epididymis*, \% & 75 & 30 \\
$\quad$ Palpation of a nodule, \% & - & 25 \\
$\quad$ Elevated testis, \% & 25 & - \\
\hline
\end{tabular}

${ }^{*} \mathrm{p}$ value $<0.05$ of patients with TT tended to present to the emergency department within the first $24 \mathrm{~h}$ following the onset of pain versus $35 \%$ of TAT patients. TAT cases were significantly more likely to present after $48 \mathrm{~h}$ than TT cases (48 versus $15 \% ; \mathrm{p}<0.05$ ). A number of investigative procedures were performed prior to surgery. These routinely included WBC and urine analysis. While no signs of urinary infections were found in any of the investigated cases, leukocytosis was found in $25 \%$ of TAT and $36 \%$ of TT cases. In recent years, Doppler ultrasound scanning became available and helped diagnose 2 TT cases prior to surgery.

Upon surgery, all torted appendages were excised. Following intervention, only 1 TAT case suffered a scrotal hematoma. All other cases were discharged without further complications. In TT cases, the viability of torted testes was assessed visually. In $90 \%$ of TT cases, orchidopexy was performed following de-torsion of an apparently salvageable testis.
It routinely involved fixing the testis with 2 silk polar stitches to the tunica albuginea. Orchidectomy was directly performed in 2 cases, where the testes were found already necrosed at the time of surgery. One of those patients had presented after $48 \mathrm{~h}$, and the other almost 4 days after the onset of symptoms. Contralateral orchidopexy was routinely performed in all TT cases to avoid subsequent torsion.

No postoperative complications were recorded for these cases. The average stay in hospital for TAT cases was 2.5 days $(\mathrm{SD}=1.1)$ and 4 days for TT cases $(\mathrm{SD}=2.3)$. All patients were followed up for a period of 2-8 weeks. During that period of observation, only one of the detorted testes subsequently atrophied in a case who had had symptoms for more than $48 \mathrm{~h}$, yielding a success rate of $85 \%$. No complications were found upon follow-up among TAT patients. 


\section{Discussion}

Acute scrotal pain and swelling can be a surgical emergency when TT cannot be ruled out. In a 10-year series from Al-Jahra Hospital, Kuwait, $57 \%$ of 120 ASS cases among children and adolescents were found to be torsions upon surgical exploration. Most of these cases (40\%) involved appendages rather than the testis itself. An additional 15\% involved direct trauma to the genital area where emergency surgery was justifiable. In the remaining $28 \%$ of cases, an accurate diagnosis could have helped theoretically to avoid surgical exploration. However, difficulties in obtaining a clear history from children, as well as ambiguous signs such as scrotal swelling, redness and tenderness render a definite clinical diagnosis almost impossible. Investigations that can help the clinician to make an accurate diagnosis in ASS are yet to be developed. Radionuclide scanning and Doppler ultrasound examinations are two recommended investigations. In clinical practice, the above investigative techniques may, however, not be readily available. When available, they may be of limited reliability, especially in children [1, 4-6]. Surgical exploration remains crucial as an early exploration can save the testis from necrosis or atrophy.

Intrascrotal torsions are common in transpubertal and postpubertal age due to the increase in testicular mass [7-9]. Vigorous exercise, local trauma, a powerful cremasteric reflex and sexual excitement are possible precipitating factors of TT $[2,10]$. Direct trauma was found in only $15 \%$ of the 20 TT cases, but in most cases no precipitating factors were elicited. Trauma has been mentioned as a precipitating cause of TT in as many as $48 \%$ of cases in some series [11]. While cold weather was implicated in at least one review [12], an increase in the incidence of torsions in winter was not found in the Al-Jahra series. Most reviews of torsions indicated that testicular appendages are more often involved than the testes, and that the left scrotal contents are more often involved than the right ones [8, 13-15].These findings were also reproduced in this series.

Patients with TT present with sudden, severe scrotal pain associated with constitutional symptoms, while those with TAT present with gradual, less severe pain. The severity of pain in TT cases explains the shorter delay in seeking medical care found in this series, compared to the delay in TAT cases. A salvage rate of $70 \%$ has been reported when surgical intervention was performed within $12 \mathrm{~h}$ of pain, and it dropped to $20 \%$ when surgery was delayed for more than $12 \mathrm{~h}$ depending on the degree of twist [16]. The immediate prognosis of TT cases treated at Al-Jahra Hospital has been remarkably good in terms of viability of the torted testis ( $85 \%$ of cases), even when the torsion had lasted almost 2 days prior to intervention ( $20 \%$ of cases). These results indicate that a relatively long history of pain does not preclude the salvage of testis although it makes it less likely.

Common nontorsion ASS etiologies found in this series included idiopathic scrotal edema, epididymo-orchitis and hydrocele. Idiopathic scrotal edema occurs primarily in prepubertal age and remains of unknown origin although allergic rectivity has been mentioned [17]. Children present with ASS, often bilateral, and extending at times to the penis and perineum. The scrotal contents are normal, and the disease is self-limiting, with resolution occurring in 1-4 days. Therapy is supportive, and there is some evidence that the addition of antihistamines may speed up the recovery [18]. ASS due to epididymo-orchitis are often accompanied by systemic symptoms and signs associated with urinary tract infection. In boys, infection is often secondary to an underlying congenital or acquired structur- 
al urological abnormality. The disease is often difficult to diagnose as urine analysis may be normal and the urine sterile. Treatment includes surgical exploration of the scrotum content, and correction of the urogenital tract anomaly leading to infection [19]. ASS due to hydrocele is usually associated with a patent processus vaginalis. Swelling is often precipitated in infant boys by intra-abdominal pressure caused by upper respiratory tract infection or an episode of constipation. These swellings are usually not tender, transluminant, and tend to resolve by 18 months of age. A swelling persisting beyond 2 years must be evacuated surgically [20]. Scrotal swelling can be an uncommon manifestation of HenochSchönlein disease [21]. One case was found in our 10-year series.

Primary health care physicians in the Jahra district and elsewhere, especially those deal- ing with children and young adolescents, should continue to educate the public to recognize TT. The awareness of parents should be raised to ensure that any acute onset of scrotal pain in children and young adults will be brought immediately to the attention of health care workers. In turn, health care workers should be prompt in determining whether a case of ASS can be diagnosed without surgical exploration. In cases where systemic signs are absent, urine analysis is negative, and the urine is sterile, immediate surgery must be indicated. Even in the presence of such signs, and a history with risk factors such as direct trauma or acute onset with rapid progression, a Doppler or scintigraphy scan exam, may lead to diagnosis. If these laboratory exams are not available and the patient is in the prepuberty period, surgical exploration should be indicated without delay.

\section{References}

1 Atkinson GOJ, Patrick LE, Ball TI, et al: The normal anatomical scrotum in children: Evaluation with color Doppler sonography. Am J Radiol 1992;158:613-617.

2 Cattolica EV, Karol JB, Ranken KN, Klein RS: High testicular salvage rate in torsions of the spermatic cord. J Urol 1982;128:66.

3 Public Authority on Civil Information: Health and Vital Statistics. Kuwait, 1995.

4 Middleton WD, Siegel BA, Melson GL, et al: Acute scrotal disorders: Prospective comparison of Doppler ultrasound and testicular scintigraphy. Radiology 1990;177:177-181.

5 Steinhardt GF, Boyarsky S, Mackey R: Testicular torsion: Pitfalls of color Doppler sonography. J Urol 1993;150:461-462.

6 Yazbeck S, Patriquin WB: Accuracy of Doppler sonography in the evaluation of acute conditions of scrotum in children. J Pediatr Surg 1994;29: 1270-1272.
7 Cranston DW, Moisey CV: The management of acute scrotal pain. Br J Surg 1983;70:505-506.

8 Knight PJ, Vassy LE: The diagnosis and treatment of acute scrotum in children and adolescents. Ann Surg 1984;200:664-673.

9 Williamson RCN: The continuing conundrum of testicular torsion. $\mathrm{Br}$ J Surg 1985;72:509.

10 Cos LR, Rabinowitz R: Traumainduced testicular torsion in children. J Trauma 1982;22:244-246.

11 Cass AS, Cass BP, Veeraraghavan $\mathrm{K}$ : Immediate exploration of the unilateral acute scrotum in young male subjects. J Urol 1980;124:829832.

12 Shukla RB, Kelly DG, Daly L, Guiney EJ: Association of cold weather with testicular torsion. BMJ 1982; 285:1459-1460.

13 Scoglund RW, McRoberts JW, Ragda H: Torsion of the spermatic cord: A review of literature and analysis of 70 new cases. J Urol 1970;140:604607.
14 McCombe AW, Scobie WG: Torsion of scrotal contents in children. Br J Urol 1988;61:148-150.

15 Schul MW, Keating MA: Acute paediatric scrotum. J Emerg Med 1993; 11:565-577.

16 Fenner MN, Roszhart DA, Texter JH Jr: Testicular scanning: Evaluating the acute scrotum in the clinical setting. Urology 1991;38:237-241.

17 Son KA, Koff SA: Evaluation and management of the acute scrotum. Prim Care 1985;12:637-646.

18 Najmaldin A, Burge DM: Acute idiopathic scrotal oedema: Incidence, manifestations and aetiology. Br J Surg 1987;74:634-635.

19 Anderson PAM, Giacomantonio JM, Schwarz RD: Acute scrotal pain in children: Prospective study of diagnosis and management. Can Med J 1989;32:29-32.

20 Rabinowitz R, Hulbert WC Jr: Acute scrotal swelling. Urol Clin North Am 1995;22:101-105.

21 Loh HS, Jalan OM: Testicular torsion in Henoch-Schönlein syndrome. BMJ 1974;2:96-97. 